\title{
THE CONCATENATIONS OF ELECTROCARDIOGRAPHIC PARAMETERS AT THE ANAEROBIC THRESHOLD
}

\author{
Virginija Bertašiūtė ${ }^{1}$, Algė Daunoravičienė ${ }^{1}$, Kristina Berškienè $\dot{1}^{1}$ Helmut Schwela ${ }^{2}$ \\ Lithuanian University of Health Sciences ${ }^{l}$, Kaunas, Lithuania \\ Reham Kreuz'2, Erfurt, Germany
}

\begin{abstract}
Background. An anaerobic threshold has been an important index of performance for assessing cardiopulmonary and muscle integration during aerobic exercise. The analysis of electrocardiographic parameters concatenations can be used to describe the physiological changes in the whole body during physical load. Research aim was to evaluate the concatenations of electrocardiographic parameters in different physical ability men group at the aerobic threshold during bicycle ergometry.

Methods. The research contingent consisted of 90 healthy men who according to the power achieved at the anaerobic threshold were divided into 3 groups, and $17 \mathrm{men}$ who had increased blood pressure and were assigned to a group of health problems. The following tests were used: anthropometric measurements, electrocardiography, bicycle ergometry, spiroergometry and mathematical statistics. During bicycle ergometry the pulmonary gas exchange rates were collected, which was used to establish the anaerobic threshold.

Results. This research has shown changes in the functional parameters of the cardiovascular system and interparametric concatenations of different fractal levels at the anaerobic threshold. This study established that the best results were obtained in the high aerobic power group.

Conclusions. This research established that the functional parameters of the cardiovascular system depended on the physical ability of subjects. At the anaerobic threshold in the high aerobic power group, the body metabolism and regulatory systems (JT/QRS) and heart and body (RR/QRS) interaction was weaker, and the heart metabolism and regulatory systems $(\mathrm{RR} / \mathrm{JT})$ interaction was stronger than in other research groups $(\mathrm{p}<.05)$.
\end{abstract}

Keywords: physical load, anaerobic threshold, concatenations of the electrocardiographic parameters.

\section{INTRODUCTION}

$\Lambda$ properly selected physical activity supports the personal optimum physical capacity, guaranteeing people's participation in all spheres of life (Hobbs et al., 2013). Scientific research has shown that regular aerobic and adequately dosed physical load reduces the risk of developing cardiovascular diseases (Ross \& Bradshaw, 2009; Schembre \& Riebe, 2011), increases human body physical capabilities (Martinmäki, Häkkinen, Mikkola, \& Rusko, 2008; Malinauskas, Dumčienè, Mamkus, \& Venckūnas, 2014) and improves the quality of life (Dale et al., 2013). It is important to choose an optimal physical exercise by establishing anaerobic threshold
(AT), because above this level exhaustion and intramuscular pain are caused (Hofmann, Bunc, Leitner, Pokan, \& Gaisl, 1994; Reilly \& Ekblom, 2005). It is important for sportsmen to learn how to expand their AT in order to work longer and more efficiently (Jones \& Carter, 2000; Reis et al., 2013). It is possible to have a higher threshold by repeating training near the AT, whaich will increase the body efficiency at burning oxygen and achieving the best sports results (Burnley \& Jones, 2007; McKay, Paterson, \& Kowalchuk, 2009). Usually AT is estimated by using either ventilatory measures (ventilatory threshold) or blood lactate 
measures (lactate threshold) (Stedman, 2012). In our research we used ventilatory measurement.

Peculiarities and opportunities of human adaptation to physical load are relevant tasks of physiology, sports and clinical medicine (Vainoras, Šmidtaite, Bikulčienè, \& Gargasas, 2011). There are many research works which emphasize the unity of the body functions (Šmidtaite, Navickas, Vainoras, Bikulčienè, \& Poškaitis, 2009), synergic interaction (Bikulčienè, Venskaitytė, \& Jaruševičius, 2014) and show informative advantages of complex, integral and integrated assessments (ŽumbakytèŠermukšnienė, Kajėnienè, Berškienė, Daunoravičienė, \& Sederevičiūtè-Kandratavičienè, 2012). The further progress of medical diagnostic technologies is unthinkable without the development and usage of non-linear analysis methods based on chaos and complex systems theories (Berškiene, Navickas, \& Vainoras, 2013). In sports medicine and clinical practice one of the most popular tests of the body adaptation to physical load is bicycle ergometry test.

An anaerobic threshold has been an important index of performance for assessing cardiopulmonary and muscle integration during aerobic exercise (Reis et al., 2013). The most common diagnostic tool which reflects a cardiac function is an electrocardiogram (ECG). It is a simple non-invasive method and the ECG parameters can be used to describe the physiological changes in the whole body (Vainoras et al., 2011). Such studies will allow evaluating the changes of the body complexity during various interventions, identifying differences of body reactions in groups of different physical ability, and selecting suitable physical workload.

The aim of the study was to evaluate the concatenations of durational electrocardiographic parameters in different physical ability men's groups at the aerobic threshold during bicycle ergometry.

\section{METHODS}

Research subjects. The investigated contingent consisted of 90 men (20-66 years old) who volunteered to participate in this study (characteristics are presented in Table 1). The healthy men were divided into 3 groups according to the power level reached at the anaerobic threshold (in weak aerobic power group (WAPG) the average of anaerobic threshold was $183.33 \pm 3.38 \mathrm{~W}$ $(n=33)$, in moderate aerobic power group (MAPG) the average of anaerobic threshold was $247.73 \pm 3.50 \mathrm{~W} \quad(\mathrm{n}=30)$ and in high aerobic power group (HAPG) the average of anaerobic threshold was $315.00 \pm 6.67 \mathrm{~W}(\mathrm{n}=10)$ and 17 men (the average of anaerobic threshold $-236.76 \pm$ $12.15 \mathrm{~W} ; 47.82 \pm 2.48$ years of age; the body mass index $-27.41 \pm 1.16 \mathrm{~kg} / \mathrm{m}^{2}$ of weight), who had increased blood pressure and were assigned to a group of persons with health problems. Initially, the data were collected from 102 men, but 12 cases were withdrawn from the final analysis due the data failure. The subjects were informed about the experimental procedures to which they would be submitted and signed the informed consent form before taking part in the study. The volunteers were free to withdraw from the study at any time without any consequences. The study was approved by the Regional Ethics committee.

The following methods were used in the research:anthropometric measurements, electrocardiography, blood pressure measurement, bicycle ergometry, spiroergometry and mathematical statistics. During bicycle ergometry the pulmonary

Table 1. Characteristics of the investigated continge nt

\begin{tabular}{|c|c|c|c|c|c|}
\hline The research group & $\begin{array}{c}\text { Weak aerobic } \\
\text { power group } \\
(\mathbf{n}=\mathbf{3 3})\end{array}$ & $\begin{array}{c}\text { Moderate aerobic } \\
\text { power group } \\
(\mathbf{n}=\mathbf{3 0})\end{array}$ & $\begin{array}{c}\text { High aerobic power } \\
\text { group } \\
\mathbf{( n = 1 0 )}\end{array}$ & $\begin{array}{c}\text { Health problem } \\
\text { group } \\
(\mathbf{n}=\mathbf{1 7})\end{array}$ & $\mathbf{p}<. \mathbf{0 5}$ \\
\hline $\begin{array}{c}\text { The average of anaerobic } \\
\text { threshold } \\
(\mathbf{w})\end{array}$ & $183.33 \pm 3.38$ & $247.73 \pm 3.50$ & $315.00 \pm 6.67$ & $236.76 \pm 12.15$ & $\begin{array}{c}*, * *, * * *, * * * *, \\
* * * * * *\end{array}$ \\
\hline $\begin{array}{c}\text { Age } \\
(\mathbf{m})\end{array}$ & $45.93 \pm 2.31$ & $40.93 \pm 1.70$ & $36.70 \pm 3.05$ & $47.82 \pm 2.48$ & $* * * * * *$ \\
\hline $\begin{array}{c}\text { Body mass index } \\
\left(\mathbf{k g} / \mathbf{m}^{2}\right)\end{array}$ & $25.03 \pm 0.42$ & $24.46 \pm 0.37$ & $24.00 \pm 0.67$ & $27.41 \pm 1.16$ & $\mathrm{NS}$ \\
\hline
\end{tabular}

Note. $*$ - statistical difference between WAPG and MAPG, $* *$ - statistical difference between WAPG and HAPG, *** - statistical difference between WAPG and HPG, **** - statistical difference between MAPG and HAPG, ***** - statistical difference between MAPG and HAPG, $* * * * * *$ - statistical difference between HAPG and HPG; NS - no significant difference. 
gas exchange rates were collected, which was used to establish the anaerobic threshold.

Experimental protocol. All subjects completed a form about their health condition before participating in the research. Their anthropometric measurements (i. e. height, weight) were carried out. The subjects were familiarized with the experimental environment and the research personnel. After the initial measurements had been done, the participants without warm-up performed a computerized bicycle exercise stress test. A short-term provocative research protocol was used. The initial workload performed by all subjects was $50 \mathrm{~W}$, and it was increased by $25 \mathrm{~W}$ every minute up to reaching sub-maximal power. The frequency of pedalling was 60 rotations/ min. During the test the electrocardiographic and the pulmonary gas exchange parameters were synchronically and continuously registered during whole bicycle ergometry test. The ventilatory variables were obtained through a computer-aided spiroergometric measurement system. The device presents the power values $(\mathrm{W})$, oxygen consumption $\left(\mathrm{VO}_{2}\right)$, carbon dioxide production $\left(\mathrm{VCO}_{2}\right)$, minute ventilation (VE) and heart rate (HR) applied at the exact time. The respiratory exchange ratio (RER) was also calculated and recorded in the research. The power applied to the cycle ergometer during exercise protocols was controlled by the system through an interface with the bicycle. The anaerobic threshold was established by the pulmonary gas exchange rate $\left(\mathrm{O}_{2} / \mathrm{CO}_{2}\right)$, when the increased alveolar $\mathrm{CO}_{2}$ output relative to $\mathrm{O}_{2}$ uptake and registered respiratory exchange ratio (RER) were above 1 .

The computerized electrocardiographic registration and the analysis system "KaunasLoad", developed at the Institute of Cardiology of Lithuanian University of Health Sciences, were used for evaluating the functional state of the cardiovascular system. ECG parameters were measured for each cardio cycle. The durational
ECG parameters assessed were: duration of RR interval (ms) (RR), duration of JT interval (ms) (JT) and duration of QRS interval (ms) (QRS). Selected ECG parameters represent different fractality levels of the body: RR and JT describe systemic, QRS - cardiac intrinsic regulatory processes. New nonlinear analysis methods, such as second order matrix analysis, were used for concatenations evaluation. Concatenations which represent interactions of components of various body systems and changes according to the integration evaluation model were assessed: discriminant between RR and JT parameters (RR/JT), discriminant between $\mathrm{RR}$ and QRS parameters (RR/QRS), discriminant between JT and QRS parameters (JT/QRS).

Data processing and statistical analysis. The data were analysed using SPSS 16.0 for Windows programme. The Mann - Whitney test was applied for comparison of two independent samples. The alpha level of $p<.05$ was required for statistical significance. Group data are presented as mean (m) \pm standard error of the mean (SEM). The parameters were rated by the maximum and minimum value.

\section{RESULTS}

ECG durational RR, JT and QRS parameters at the AT during bicycle ergometry are illustrated in Table 2. RR was statistically significantly shorter in the HAPG than in other groups at the AT, what reflects the better state of the body regulatory system in that group $(p<.05)$. JT also was statistically significantly shorter in the HAPG than in other groups, which shows the better metabolism and supplying system's state of the body at the AT in that group ( $<<.05)$. QRS was statistically significantly longer in the HAPG than in other groups at the AT, which demonstrates the better state of the regulatory system at the organs' level in that group $(p<.05)$.

Analysing concatenation of ECG parameters, it was established that the heart metabolism and

Table 2. ECG durational parameters at the anaerobic threshold during bicycle ergometry

\begin{tabular}{|c|c|c|c|c|c|}
\hline Parameters & $\begin{array}{c}\text { Weak aerobic } \\
\text { power group }\end{array}$ & $\begin{array}{c}\text { Moderate aerobic } \\
\text { power group }\end{array}$ & $\begin{array}{c}\text { High aerobic } \\
\text { power group }\end{array}$ & $\begin{array}{c}\text { Health problem } \\
\text { group }\end{array}$ & p $<.05$ \\
\hline RR at AT, ms & $423.84 \pm 10.01$ & $386.25 \pm 5.88$ & $359.99 \pm 7.86$ & $399.12 \pm 10.82$ & $*, * *, * * * *, * * * * * *$ \\
\hline JT at AT, ms & $167.42 \pm 3.67$ & $152.39 \pm 2.57$ & $142.18 \pm 4.29$ & $162.47 \pm 4.56$ & $*, * *, * * * * * *$ \\
\hline QRS at AT, ms & $86.38 \pm 0.92$ & $88.73 \pm 1.12$ & $90.20 \pm 3.03$ & $88.09 \pm 1.46$ & $\mathrm{NS}$ \\
\hline
\end{tabular}

Note. * - statistical difference between WAPG and MAPG, ** - statistical difference between WAPG and HAPG, *** - statistical difference between WAPG and HPG, **** - statistical difference between MAPG and HAPG, *****-- statistical difference between MAPG and HAPG, $* * * * * *$ - statistical difference between HAPG and HPG; NS - no significant difference. 
regulatory systems (RR/JT) interaction was stronger in HAPG than in other research groups $(p<.05)$ (Figure 1). This shows strengthening of functional links between regulatory and supplying systems at the systemic level at the AT in the better physical ability group.

A concatenation between RR and QRS parameters reflects connection between the two levels of regulatory systems (body and organ levels) (Figure 2). This index in HAPG was weaker than in other research groups $(p<.05)$, so the better regulations between heart and body were in lower physical ability groups.

At AT JT/QRS in the high aerobic power group was weaker than in other research groups $(p<.05)$ (Figure 3). Based on our research results it can be said that the body metabolism and regulatory

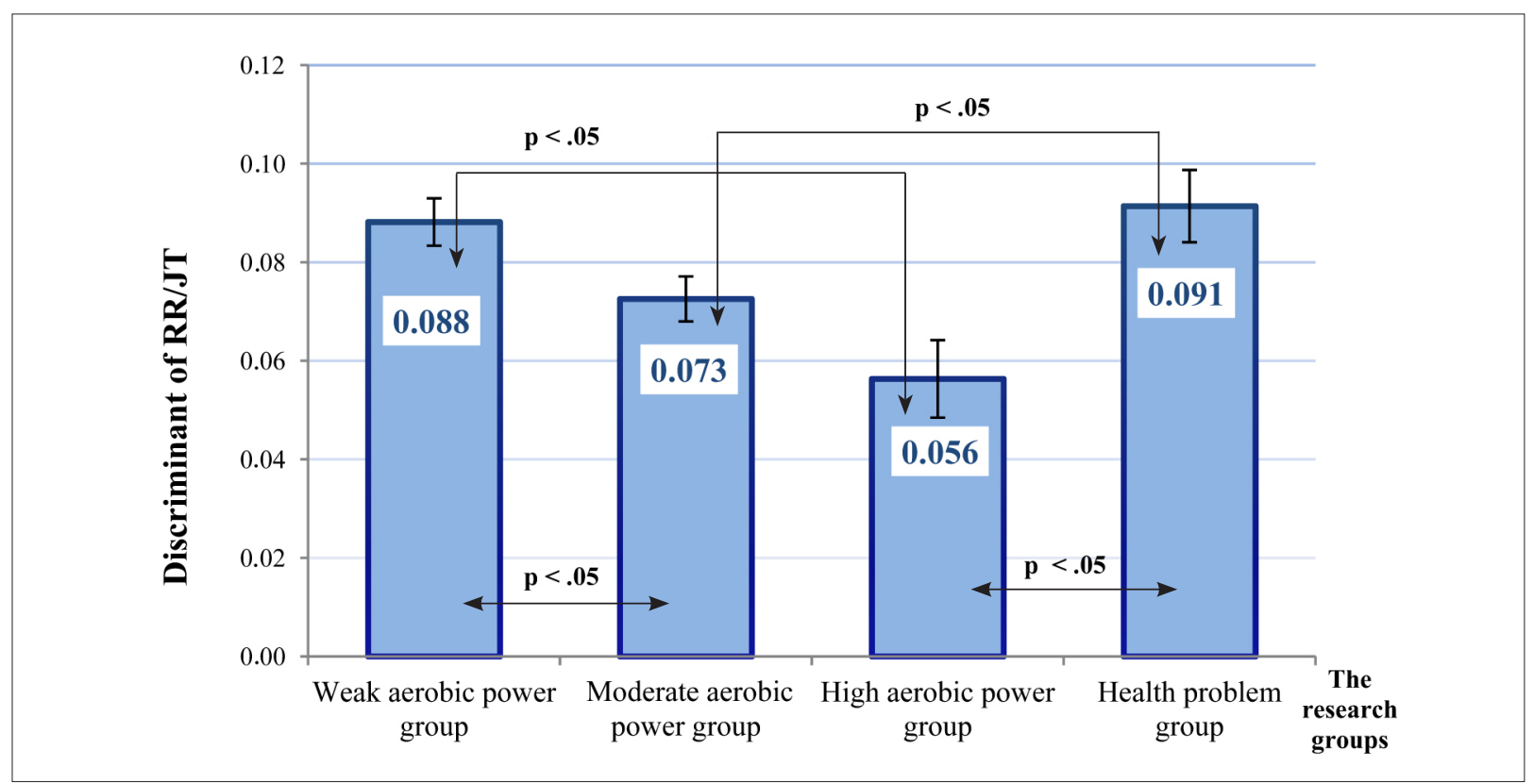

Note. $\mathrm{p}<.05-$ statistical difference between groups.

Figure 1. Discriminant of concatenation between RR and JT parameters at the anaerobic threshold during bicycle ergometry

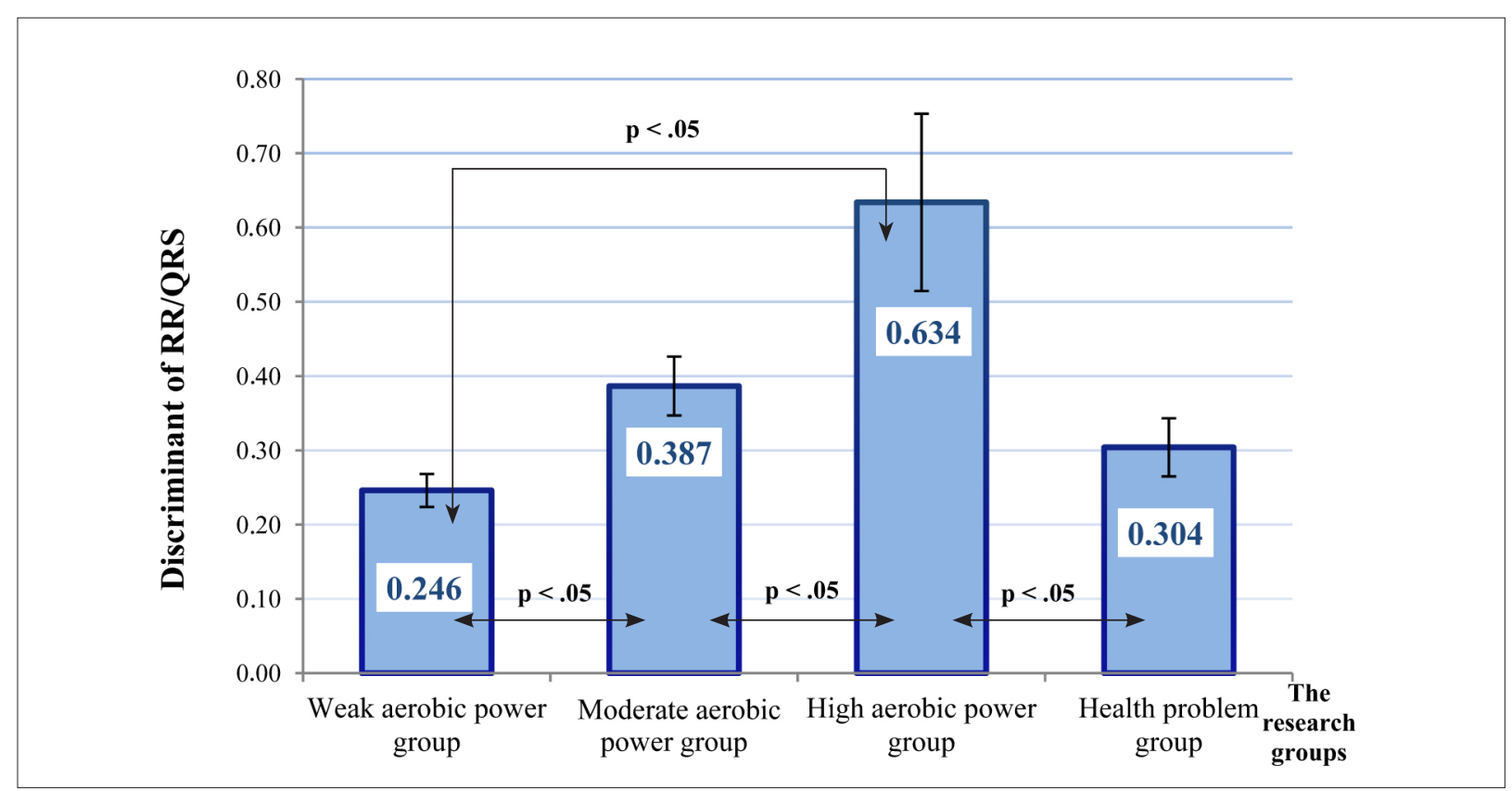

Note. $\mathrm{p}<.05-$ statistical difference between groups.

Figure 2. Discriminant of concatenation between RR and QRS parameters at the anaerobic threshold during bicycle ergometry 
systems concatenations depended on physical ability and it decreased in HAPG.

A concatenation of ECG parameters represents supplying system function at various levels of fractality and its link with the respiratory function. The pulmonary gas exchange parameter values are given in Table 3. The best values were established in the high aerobic power group than in other groups at the AT.
Heart rate values of different group participants during bicycle ergometry at the AT are illustrated in Figure 4.

We established that the cardiovascular system reaction at the anaerobic threshold depended on the men's physical ability - the heart beat was biggest in the high aerobic power group $(\mathrm{p}<.05)$.

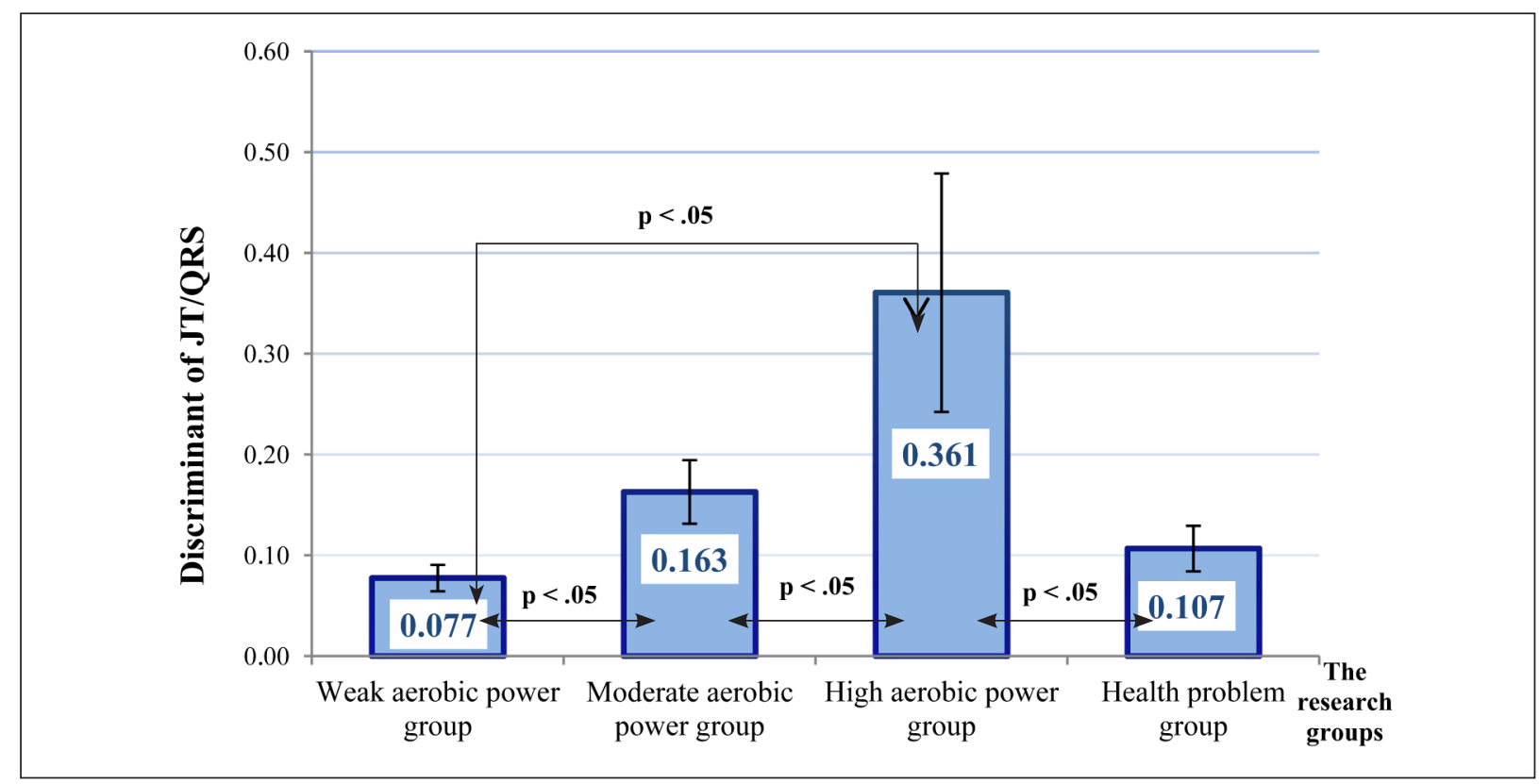

Note. $\mathrm{p}<0.05$ - statistical difference between groups.

Figure 3. Discriminant of concatenation between JT and QRS parameters at the anaerobic threshold during bicycle ergometry

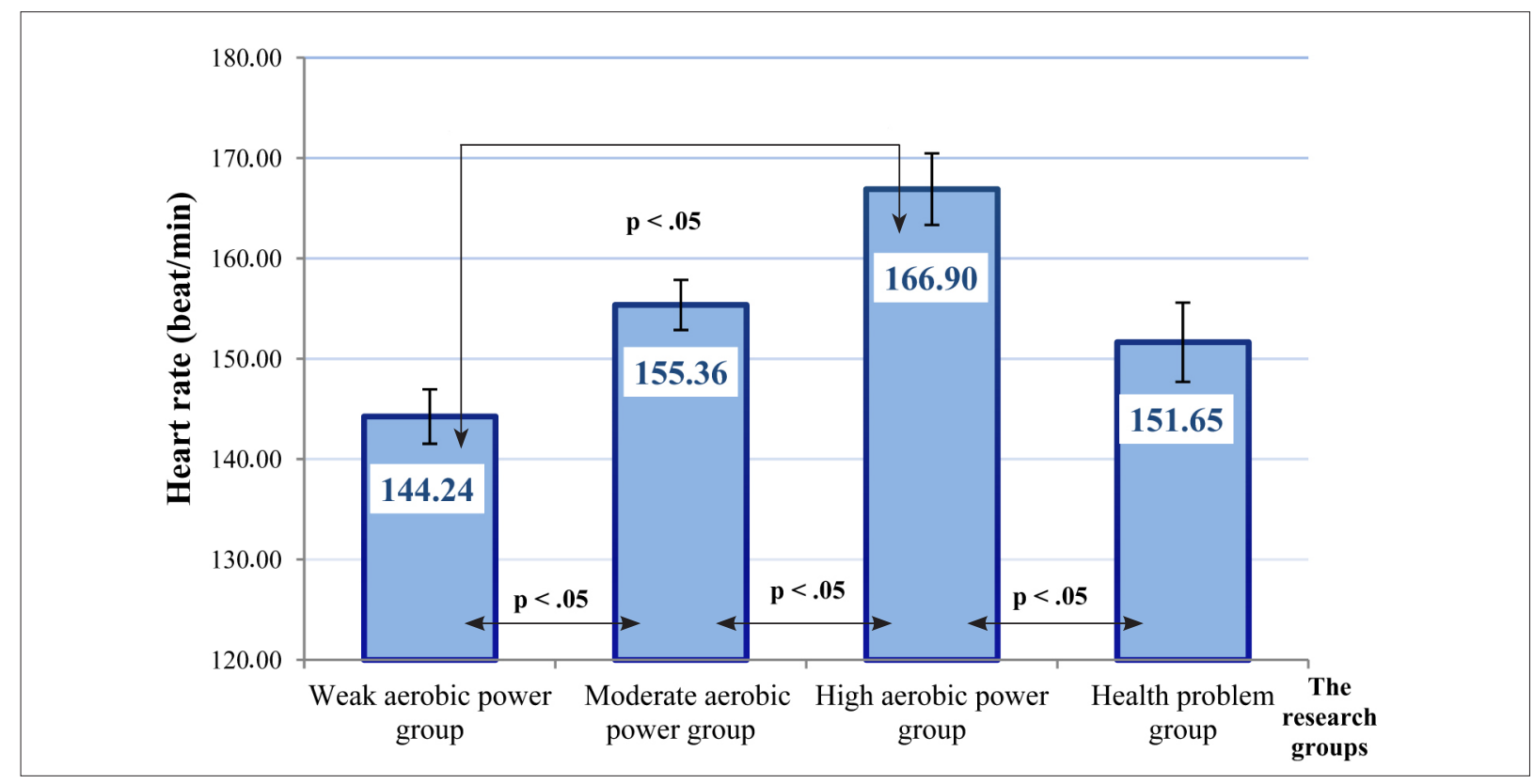

Note. $\mathrm{p}<.05-$ statistical difference between groups.

Figure 4. Heart rate at the anaerobic threshold during bicycle ergometry 
Table 3. Spirometric parameter values at the anaerobic threshold during bicycle ergometry

\begin{tabular}{|c|c|c|c|c|c|}
\hline Parameters & $\begin{array}{l}\text { Weak aerobic } \\
\text { power group }\end{array}$ & $\begin{array}{c}\text { Moderate aerobic } \\
\text { power group }\end{array}$ & $\begin{array}{l}\text { High aerobic } \\
\text { power group }\end{array}$ & $\begin{array}{c}\text { Health problem } \\
\text { group }\end{array}$ & $\mathrm{p}<.05$ \\
\hline 0.Pulse AT, $\mathrm{ml} /$ beat & $15.96 \pm 0.36$ & $20.67 \pm 0.43$ & $24.94 \pm 0.79$ & $20.05 \pm 0.89$ & $*, * *, * * * *, * * * * * *$ \\
\hline Max0 ${ }_{2}$ Pulse, $\mathrm{ml} /$ beat & $18.57 \pm 0.51$ & $22.56 \pm 0.47$ & $26.66 \pm 0.95$ & $21.31 \pm 0.87$ & $*, * *, * * * *, * * * * * *$ \\
\hline $\mathrm{VE}$ at $\mathrm{AT}, \mathrm{l} / \mathrm{min}$ & $61.16 \pm 2.13$ & $81.29 \pm 2.53$ & $104.06 \pm 4.79$ & $77.96 \pm 4.39$ & $*, * *, * * * *, * * * * * *$ \\
\hline MaxVE, $1 /$ min & $99.35 \pm 3.47$ & $116.79 \pm 4.28$ & $119.99 \pm 9.92$ & $99.25 \pm 4.98$ & $*, * *, * * * * * *$ \\
\hline
\end{tabular}

\section{DISCUSSION}

The purpose of this study was to evaluate the concatenations of durational electrocardiographic parameters in different physical ability men's groups at the aerobic threshold during bicycle ergometry. The bicycle ergometry test which was used in our investigation engaged a large muscle mass, so the functional capacity of the cardiovascular system plays an important role (Papievienè, Poderiené, Trinkūnas, Grūnovas, \& Poderys, 2014). This research has shown changes in the functional parameters of a cardiovascular system, i. e. the electrocardiographic parameters, and the changes of inter-parametric concatenations (complexity) of the different fractal levels at the anaerobic threshold. We demonstrated that the best results were shown in the high aerobic power group.

Hofmann et al. (1994) did not observe significant differences between the threshold detected through the HR break point and blood lactate change point of sedentary women performing exercise with a non-continuous loading protocol. Bunc, Hofmann, Leitner, and Gaisl (1995) observed that AT obtained through HR did not demonstrate significant differences when compared to AT measured through the ventilatory method, lactate or from the electromyography of the vastus medialis of the thigh. Reis et al. (2013) established that the HR response is equally effective in detecting AT when compared to other methods employed in healthy elderly men. Their findings are relevant to the physical therapy and they support the possible use of HR as the capacity means to accurately detect AT and prescribe exercise at the safest and most appropriate individualized intensity to improve the functional capacity and the quality of life in aging. The results obtained during our study showed that HR was the highest in high aerobic power group at the anaerobic threshold during bicycle ergometry $(\mathrm{p}<.05)$.
We are aware that our study has limitations, particularly with regard to the small sample size and the constrained characteristics of our study population, which prevented the evaluation of factors such as age and level of fitness, each of which is known to influence the variables of interest. Also, we are aware that the choice of a rapid work rate incremental protocol may have influenced the results utilized, i. e. different results may be observed if a slower work rate increment protocol is used. We took precautions to limit errors in the calibration procedures, with all equipment being calibrated before each test and all tests being performed. Thus, our investigation should be considered as a pilot study conducted at extreme altitude, with the conclusions only being applicable to healthy untrained adults.

Our results suggest a possibility to determine AT during bicycle ergometry test using durational ECG parameters analysed and it is a less expensive method compared to those that use expired gas measurements, and may therefore be utilized in sports medicine and in extreme conditions such as high altitude.

This study of ECG parameters and their concatenations with the help of new mathematical methods of analysis opens the new opportunities for practical application of complex systems theory in order to reveal the changes at the AT.

Additionally, our results suggest that the use of these tools in other populations presenting cardiorespiratory and metabolic disease risk factors should be investigated in future studies.

\section{CONCLUSIONS}

In this research it was established that the functional parameters of the cardiovascular system depended on the physical ability of subjects the heart beat at the anaerobic threshold was the highest in the high aerobic power group $(\mathrm{p}<.05)$. 
At the anaerobic threshold in the high aerobic power group, the body metabolism and regulatory systems (JT/QRS) and heart and body (RR/QRS) interaction were weaker, and the heart metabolism and regulatory systems $(\mathrm{RR} / \mathrm{JT})$ interaction was stronger than in other research groups $(\mathrm{p}<.05)$.

\section{REFERENCES}

Berškienė, K., Navickas, Z., \& Vainoras, A. (2013). Heart rate complexity changes during bicycle ergometry. 18 th annual congress of the European college of sport science: Book of abstracts (p. 612). Barcelona: Spain.

Bikulčienè, L., Venskaitytė, E., \& Jaruševičius, G. (2014). The estimation of human vital signs complexity. International Journal of Medical, Pharmaceutical Science and Engineering, 8(1), 39-44.

Bunc, V., Hofmann, P., Leitner, H., \& Gaisl, G. (1995). Verification of the heart rate threshold. European Journal of Applied Physiology, 70, 263-269. doi: 10.1007/ BF00238574

Burnley, M., \& Jones, A. M. (2007). Oxygen uptake kinetics as determinant of sports performance. European Journal of Sport Science, 7(2), 63-79. doi: 10.1080/17461390701456148

Dale, C. E., Bowling A., Adamson, J., Kuper, H., Amuzu, A., Ebrahim, S., ... Nuesch, E. (2013). Predictors of patterns change in health-related quality of live in older women over 7 years: Evidence from a prospective cohort study. Age and Ageing, 42(3), 312318.

Hobbs, N., Godfrey A., Lara, J., Errington, L., Meyer, T. D., Rochester, L., Sniehotta, F. F. (2013). Are behavioral interventions effective in increasing physical activity at 12 to 36 months in adults aged 55 to 70 years? A systematic review and meta-analysis. BMC Medicine, 1(11), 75. doi:10.1186/1741-7015-11-75

Hofmann, P., Bunc, V., Leitner, H., Pokan, L., \& Gaisl, G. (1994). Heart rate threshold related to lactate turn point and steady-state exercise on a cycle ergometer. European Journal of Applied Physiology, 69, 132-139. doi: 10.1007/BF00609405

Jones, A. M., \& Carter, H. (2000). The effect of endurance training on parameters of aerobic fitness. The Journal of Sports Medicine, 29(6), 373-386. doi: 10.2165/00007256-200029060-00001

Malinauskas, R., Dumčienè, A., Mamkus, G., \& Venckūnas, T. (2014). Personality traits and exercise capacity in male athletes and non-athletes. Perceptual and Motor Skills, 118(1), 145-162. doi: 10.2466/29.25. PMS.118k13w

Martinmäki, K., Häkkinen, K., Mikkola, J., \& Rusko, H. (2008). Effect of low-dose endurance training on heart rate variability at rest and during an incremental maximal exercise test. European Journal of Applied Physiology, 104(3), 541-548. doi: 10.1007/s00421-008-0804-9

Received on April 14, 2014

Accepted on June 09, 2014
McKay, B. R., Paterson, D. H., \& Kowalchuk, J. M. (2009). Effect of short-term high-intensity interval training vs. continuous training on $\mathrm{O}_{2}$ uptake kinetics, muscle deoxygenation, and exercise performance. European Journal of Applied Physiology, 107(1), 128138. doi: 10.1152/japplphysiol.90828.2008

Papievienè, V., Poderienè, K., Trinkūnas, E., Grūnovas, A., \& Poderys, J. (2014). Cardiac function and muscular oxygen desaturation in sprint and endurance cohorts during the incremental bicycle ergometry. Baltic Journal of Sport and Health Sciences, 1(92), 49-54.

Reilly, T., \& Ekblom, B. (2005). The use of recovery methods post-exercise. Journal of Sports Sciences, 23(6), 619-627. doi: 10.1080/02640410400021302

Reis, M. S., Berton, D. C., Arena, R., Catai, A. M., Neder, J. A., \& Borghi-Silva, A. (2013). Determination of anaerobic threshold through heart rate and near infrared spectroscopy in elderly healthy men. Brazilian Journal of Physical Therapy, 17(5), 506-515. doi: 10.1590/S1413-35552012005000115

Ross, R., \& Bradshaw, A. J. (2009). The Future of Obesity Reduction: Beyond Weight Loss. Nature Reviews Endocrinology, 5, 319-326.

Schembre, S. M., Riebe, D. A. (2011). Non-exercise estimation of $\mathrm{VO}_{2} \max$ using the international physical activity questionnaire. Measurement in Physical Education and Exercise Science, 15(3), 168-181. doi: 10.1080/1091367X.2011.568369

Stedman, T. L. (2012). Medical dictionary for the health professions and nursing (p. 2339). Walters Kluwer Health/Lippincott Williams \& Wilkins.

Šmidtaitè, R., Navickas, Z., Vainoras, A., Bikulčienė, L., \& Poškaitis, V. (2009). Evaluation of coherence of t-wave in different leads. Electronics and Electrical Engineering, 5(93), 113-116.

Vainoras, A., Šmidtaitè, R., Bikulčienè, L., \& Gargasas, L. (2011). Monitoring of elderly using special matrix characteristics for analysis of ECG parameters. Biomedical engineering-2011: Proceedings of International Conference (pp. 26-29). Kaunas: KTU. Žumbakytè-Šermukšnienè, R., Kajënienè, A., Berškienè, K., Daunoravičienè, A., \& SederevičiūtèKandratavičienè, R. (2012). Assessment of the effect of anthropometric data on the alterations of cardiovascular parameters in Lithuanian elite male basketball players during physical load. Medicina, 48(11), 566-571.

Corresponding author Virginija Bertašiūtė Lithuanian University of Health Sciences Mickevičiaus str. 9, LT-44307 Kaunas Lithuania Tel +37037320028

E-mail virginija.bertasiute@1smuni.1t 